\title{
Apoptosis-related gene expression in tumor tissue samples obtained from patients diagnosed with glioblastoma multiforme
}

\author{
EVA BLAHOVCOVA $^{1}$, ROMANA RICHTEROVA ${ }^{2}$, BRANISLAV KOLAROVSZKI ${ }^{2}$, \\ DUSAN DOBROTA $^{1}$, PETER RACAY ${ }^{1}$ and JOZEF HATOK ${ }^{1}$ \\ ${ }^{1}$ Department of Medical Biochemistry, Jessenius Faculty of Medicine in Martin, Comenius University in Bratislava; \\ ${ }^{2}$ Clinic of Neurosurgery, Jessenius Faculty of Medicine in Martin, Comenius University in Bratislava \\ and University Hospital in Martin, SK-03601 Martin, Slovakia
}

Received May 27, 2015; Accepted September 28, 2015

DOI: $10.3892 /$ ijmm.2015.2369

\begin{abstract}
Tumors of the brain are very diverse in their biological behavior and are therefore considered a major issue in modern medicine. The heterogeneity of gliomas, their clinical presentation and their responses to treatment makes this type of tumor a challenging area of research. Glioblastoma multiforme (GBM) is the most common, and biologically the most aggressive, primary brain tumor in adults. The standard treatment for patients with newly diagnosed GBM consists of surgical resection, radiotherapy and chemotherapy. However, resistance to chemotherapy is a major obstacle to successful treatment. The aim of this study was to examine the changes occurring in the expression levels of apoptosis-associated genes in tumor tissue biopsy samples from 7 patients diagnosed with GBM and compare our results with a human astrocyte cell line (used as a reference) cultured under basic conditions. For molecular analysis, we used a commercial pre-designed microfluidic array to quantify the expression of 93 apoptosis-associated human genes. Significant changes in the expression levels of genes were observed in the tumor tissue samples obtained from patients with GBM. We determined significant changes in gene expression $(\mathrm{n}=32)$ in all apoptotic signaling pathways $(\mathrm{BCl}-2$, TNF, Caspases, NF-kB, IAP and CARD), while the most pronounced deregulation ( $>5$-fold) were observed in $46.9 \%$ events. The results of this study underline the importance of apoptosis in heterogenous tumor tissue. The identification of the apoptotic gene panel in tissue biopsies from patients with GBM may help improve the effectiveness of treatments for GBM in clinical practice and may broaden our understanding of brain tumor cell metabolism. Recognizing the changes in the expression of proapoptotic and anti-apoptotic genes may aid in the development of novel treatment strategies founded on a molecular basis.
\end{abstract}

Correspondence to: Dr Jozef Hatok, Department of Medical Biochemistry, Jessenius Faculty of Medicine in Martin, Comenius University in Bratislava, Mala Hora 4, SK-03601 Martin, Slovakia E-mail: hatok@jfmed.uniba.sk

Key words: apoptosis, brain tumor, glioblastoma multiforme, astrocyte cell line, gene expression

\section{Introduction}

Changes in programmed cell death and the loss of regulation in cell growth and anti-growth signals may result in uncontrolled proliferation, the disorganized growth of tissue cells and tumor formation. The malignant transformation of cells is accompanied and characterized by the disruption of genetic material and the aberrant expression of multiple genes. Tumors of the central nervous system (CNS) are characterized by heterogeneity within the cell population and are the cause of severe serious medical conditions $(1,2)$. Brain tumor cells with a low growth rate have a benign character and are classified as grade I or II, according to the World Health Organization (WHO) classification of tumors of the CNS. However, tumor cells with a malignant character are classified as grade III or IV, according to WHO, and can grow into surrounding tissue (3).

In relation to brain tumors, there is little knowledge of the genetic patterns of inheritance, and it is often difficult to diagnose a patient in the early stages of the disease. The treatment of brain tumors depends on the histological diagnosis. The mainstay of therapy is tumor resection through surgery. Post-operative radiotherapy and chemotherapy improve the survival rate of patients with high-grade brain tumors. Gliomas originate from dedifferentiated mature neural cells that have transformed into cancer stem cells (CSCs), or neural stem and progenitor cells $(2,4,5)$. Moreover, there is a close association between tumor progression and CSCs. In order for treatment to be successful, it is crucial to eliminate CSCs, which play a key role in tumor recurrence (6-8). The classification system established by WHO in 2007 divided gliomas into astrocytomas (grades I-IV), oligodendrogliomas (grades II and III), ependymomas (grades I-III) and mixed gliomas (grades II and III). Malignant gliomas are the most common type of primary brain tumor, with an annual incidence of 5/100,000 individuals (3). Glioblastoma multiforme (GBM), which is classified as grade IV according to the malignancy grading system, account for $60-70 \%$ of all gliomas (9-11). Currently, the prognosis for patients with GBM remains very poor, with the majority of patients succumbing to the disease within 1 year of diagnosis (12). The term 'multiforme' reflects the heterogeneity of this type of tumor as regards clinical presentation, genetic variability and the varying responses to treatment (13). The 
majority of glioblastomas arise de novo and are designated as primary glioblastomas, which manifest in older patients. By contrast, secondary glioblastomas develop at slower rate, by malignant progression from astrocytomas, and manifest in younger patients $(4,9,14-16)$. The mean age of patients with primary glioblastoma is 62 , and the median survival is 4.7 months, whereas patients with secondary glioblastoma have a mean age of 45 , the median survival is significantly longer (7.8 months) $(10,12)$.

Standard treatment for patients newly diagnosed GBM consists of surgical resection, radiotherapy and chemotherapy; however, resistance to clinical therapy is a major obstacle to successful treatment $(8,17,18)$. Despite extensive investigations, a cure for GBM is not currently available. Radiotherapy and chemotherapy work predominantly by inducing apoptosis (19). The unfavorable prognosis for patients with glioblastomas is also due in part to poor knowledge of alterations to the molecular pathways involved. The identification of common differences in apoptosis-related genes in the apoptotic pathway may provide new knowledge of strategies to avoid resistance to therapy in $\operatorname{GBM}(17,18,20)$. The deregulation of the normal mechanism for programmed cell death also plays an important role in the pathogenesis and progression of gliomas. The majority of spontaneous cell deaths in malignant gliomas are due to apoptosis $(11,16,21,22)$. Apoptosis can be activated by multiple pathways that differ in terms of tissue type and pathological conditions. Understanding the mechanisms involved in the apoptotic signaling pathway in glioblastomas may help us to identify target molecules for molecular therapies (23). Apoptotic pathways have been classified into two main types, the extrinsic receptor pathway and intrinsic mitochondrial pathway, depending on the origin of the death stimuli (24-26). The activation of effector caspases by apoptotic signaling pathways leads to programmed cell death (apoptosis) (27). The extrinsic apoptotic pathway is activated by the stimulation of tumor necrosis factor- $\alpha(\mathrm{TNF}-\alpha)$ or Fas cell surface death receptors. The TNF family and its corresponding receptors play important roles in cell death, as well as survival, proliferation and maturation. All members of the TNF superfamily activate the nuclear factors of the $\kappa$ light polypeptide gene enhancer in B-cells $(\mathrm{NF}-\kappa \mathrm{B})$ family, which suppresses apoptosis, cell survival and proliferation (28-30). The B-cell lymphoma-2 (BCL-2) family consists of approximately 15 proteins, which are divided into anti-apoptotic subgroups: BCL-2, BCL-xL, BCL-w, MCl1, $\mathrm{A} 1$ and the pro-apoptotic subgroup: BAX, BAK, BOK, BID, BAD, BIM, BIK, BLK, HRK, NOXA and PUMA $(27,31)$. Whereas anti-apoptotic members stabilize mitochondrial membrane potential and prevent the release of cytochrome $c$ and apoptosis-inducing factors, pro-apoptotic members lead to programmed apoptotic cell death (30,32-34). The release of cytochrome $c$ into the cytoplasm results in the formation of apoptosomes composed of cytochrome $c$, apoptotic peptidase activating factor 1 (APAF1) and deoxy-adenosine triphosphate (ATP) $(35,36)$. Apoptosomes stimulate caspases, a family of apoptosis-related cysteine proteases that initiate cell death and play critical roles in human cell apoptosis. Caspases are divided into two classes, initiator caspases-1, -2, -4, -5, -8, -9, $-10,-12$ and -13 , and effector caspases-3, -6 and -7 (30).

In previous studies, we focused on gene expression profiling in different types of healthy and tumor tissues $(37,38)$. Genomic characterization could rapidly expand our knowledge of the molecular basis of GBM, and may lead to the development of a more precise classification system which may become a prerequisite for achieving individualized clinical care for patients with glioma $(39,40)$. We hypothesized that the deregulation of the apoptotic pathway in GBM cells may contribute to tumor formation and treatment resistance. Thus, the identification of changes in apoptosis and apoptosis signaling pathway-related genes may broaden our understanding of the importance of apoptosis in heterogenous tumor tissue, and may expand our knowledge of brain tumor cell metabolism. Thus, targeting the apoptotic pathway in GBM offers a unique opportunity to develop novel therapeutic strategies that may serve to overcome tumor resistance. Furthermore, cDNA microarrays may improve gene expression patterns which are capable of predicting individual responses to therapy.

Thus, the aim of this study was to examine the changes occurring in the expression levels of apoptosis-associated genes in tumor tissue biopsy samples from 7 patients diagnosed with GBM and compare our results with a human astrocyte cell line (used as a reference) cultured under basic conditions.

\section{Materials and methods}

Cell culture. The human astrocyte (HA) cell line was purchased from ScienCell Research Laboratories (San Diego, CA, USA). The cells were cultured in $96 \%$ (v/v) astrocyte medium with $2 \%(\mathrm{v} / \mathrm{v})$ fetal bovine serum, $1 \%(\mathrm{v} / \mathrm{v})$ astrocyte growth supplement and $1 \%$ (v/v) PS solution (all from ScienCell Research Laboratories) and incubated in a humidified atmosphere with $5 \% \mathrm{CO}_{2}$ at $37^{\circ} \mathrm{C}$.

Glioblastoma samples. Native tumor tissue samples obtained during GBM tumor resections were provided by the Clinic of Neurosurgery, Jessenius Faculty of Medicine in Martin, Comenius University in Bratislava and University Hospital in Martin (Martin, Slovakia). Biopsy tissues were obtained from 7 patients, 4 males and 3 females, whose ages ranged from 55 to 88 years (median age, 65.7 years), who had not previously received radiotherapy or chemotherapy. All tumors were histologically confirmed to be glioblastomas according to the criteria of the most recent WHO Classification of CNS Tumors (3), with Ki67 levels ranging from 15 to $40 \%$ (Table I). The experimental protocols were approved by the local Ethics Committee (Jessenius Faculty of Medicine in Martin, Comenius University in Bratislava).

RNA extraction and reverse transcription. Total RNA was extracted from the HA cell line and tissue biopsy samples using TRI Reagent ${ }^{\circledR}$ (Molecular Research Center, Inc., Cincinnati, $\mathrm{OH}$, USA), according to the manufacturer's instructions. The RNA isolation quality was examined using a NanoDrop ${ }^{\circledR}$ spectrophotometer (Thermo Scientific, Waltham, MA, USA). Five micrograms of total RNA were reverse transcribed in a total volume of $14 \mu \mathrm{g}$ using a Maxima First Strand cDNA Synthesis kit (Thermo Scientific) according to the manufacturer's instructions.

Microarray analysis. The regulation of gene expression was examined using a TaqMan ${ }^{\circledR}$ Human Apoptosis Array (Applied 
Table I. Characterization of patients with glioblastoma multiforme in the present study.

\begin{tabular}{llcc}
\hline GBM no. & \multicolumn{1}{c}{ Gender } & Age (years) & Ki67 (\%) \\
\hline 1 & Male & 55 & 40 \\
2 & Male & 71 & 40 \\
3 & Male & 61 & 30 \\
4 & Female & 65 & 15 \\
5 & Female & 88 & 15 \\
6 & Male & 61 & 30 \\
7 & Female & 59 & 40 \\
Average & Male, 57.1\% & $65.71 \pm 11.03$ & $30 \pm 11.18$ \\
& Female, $42.9 \%$ & & \\
\hline
\end{tabular}

Gender, age in years and proliferation marker Ki67 levels (\%) in tumor cells of patients with glioblastoma multiforme (GBM no. 1-7).

Biosystems) based on the RT-qPCR reaction. The pre-designed 384-well microfluidic card contained an assay for 93 human apoptotic genes and 3 endogenous control genes: eukaryotic 18S rRNA (18S), $\beta$-actin (ACTB) and glyceraldehyde-3-phosphate dehydrogenase $(G A P D H)$. A reaction mixture with $100 \mathrm{ng}$ cDNA template and an equal volume of TaqMan ${ }^{\circledR}$ Gene Expression Master Mix was loaded into each line of the microfluidic card. The PCR mix was distributed into the wells by 2 centrifugations, each at $450 \mathrm{x}$ g, for $1 \mathrm{~min}$, and were sealed and loaded into the ViiA7 Real-Time PCR system (Applied Biosystems). The tissue biopsy samples were measured in duplicate, samples of the HA cell line in triplicate, data transformation was corrected for the signal from the 3 endogenous controls (18S, ACTB and GAPDH) and the level of target gene expression was determined using the $\Delta \Delta \mathrm{Ct}$ method. Genes with a significant difference in expression were considered those with an average fold change of $\leq-2.0$ or $\geq 2.0$ and statistically significant differences were those with a corresponding $\mathrm{p}$-value $<0.05$.

\section{Results}

The expression of the 93 apoptosis-related genes was examined in the tissue biopsy samples from 7 patients with diagnosed with GBM, and we used the HA cell line as a reference. The pre-designed microfluidic cards in the TaqMan ${ }^{\circledR}$ Human Apoptosis array (Applied Biosystems) contain the most significant apoptosis- and apoptosis signaling pathway-related genes and 3 internal controls (18S, ACTB and $G A P D H)$ used for data normalization.

BCL-2 family-regulated pathway. The expression patterns of the apoptotic genes differed significantly in the tissue biopsy samples obtained from the patients compared to the reference HA cell line (Fig. 1 and Table II). The significantly higher expression of the $B C L 2(\mathrm{FC}=12.45, \mathrm{p}=0.0012)$ and $B C L 2 L 2(B C L-w)$ [fold change $(\mathrm{FC})=3.23, \mathrm{p}=0.0222$ ] genes noted in the GBM tissue biopsy samples may serve as a protective factor against apoptosis. The other upregulated genes noted include the facilitator of apoptosis, BCL2L11 (BIM), which plays an important role in neuronal apoptosis and can be induced by nerve growth factor, and $B N I P 3 L, B N I P 3, B B C 3$ $(P U M A)$ and $B A D$. On the other hand, the most pronounced decrease was noted in the PMAIPl (NOXA) gene $(\mathrm{FC}=-30.78$, $\mathrm{p}=0.0015)$, and the lower expression of the $B O K(\mathrm{FC}=-3.94)$ and BCL1O (FC = -2.54) genes was also noted, indicating the increased anti-apoptotic properties of the glioblastoma tumor tissues. A statistically significant downregulation of BCL2L1 $(B C L-x L)$ and $M C L 1$ genes was also noted.

TNF receptor pathway. In the tissue biopsy samples from the patients with GBM, the altered regulation of the TNF receptor pathway (Fig. 1 and Table II) was noted, and the most pronounced change was the statistically significant decrease in the expression of TNFRSF10A $(\mathrm{FC}=-15.58, \mathrm{p}=0.0045)$, TNFRSF10B $(\mathrm{FC}=-8.30, \mathrm{p}=0.0003)$ and the increase in the expression of TNFRSFIB $(\mathrm{FC}=8.82, \mathrm{p}=0.0173)$. A slight upregulation in expression was detected in the TNFRSF 25 and TNFRSF21 genes, whereas a slight downregulation in expression was detected in the FADD, FAS and TNFRSF1A genes.

Caspases. It is clear from our results that, of the caspases, the most pronounced statistically significant increase was in observed in CASP1O expression $(\mathrm{FC}=29.46, \mathrm{p}=0.0006)$ followed by the upregulation of the associated caspases, CASPI $(\mathrm{FC}=7.41, \mathrm{p}=0.0161)$ and CASP4 $(\mathrm{FC}=2.47)$. However, the expression of $C A S P 8$ and that of the effector caspases, CASP6 and $C A S P 7$, was only slightly downregulated, suggesting that these caspases do not seem to play an important role in apoptosis in GBM (Fig. 1 and Table II).

$N F-\kappa B$ signaling pathway. Genetic analysis revealed a statistically significant upregulation of REL, NFKBIA and $T A-N F K B H$ expression, whereas a statistically significant downregulation of NFKB2 expression was detected (Fig. 1 and Table II).

Inhibitor of apoptosis (IAP) family. Baculoviral IAP repeatcontaining (BIRC) proteins are members of the IAP gene family, which encode proteins that prevent apoptotic cell death (41-43). In this study, as regards the IAP family, the most pronounced statistically significant increase in expression was noted in BIRCI ( $\mathrm{FC}=147.09, \mathrm{p}=0.0001)$ and a less pronounced decrease in expression was noted in the BIRC6 and BIRC5 genes (Fig. 1 and Table II). The NLR family, apoptosis inhibitory protein (NAIP or BIRC1) acts as a mediator of neuronal survival under pathological conditions and prevents neuronal apoptosis induced through a variety of signals $(44,45)$.

CARD family. Caspase activation and recruitment domains (CARDs) are interaction motifs that are found in a wide array of proteins, typically those involved in apoptosis $(46-48,63)$. In this study, in the tissue biopsy samples obtained from patients with GBM, the PYCARD gene was significantly upregulated and the $A P A F 1$ gene was downregulated (Fig. 1 and Table II). The downregulation of $A P A F 1$ can negatively affect apoptosome formation and may thus inhibit apoptotic cell death (49-52).

Changes observed in the expression of other genes. There was a slight, but statistically significant increase in the expression of 

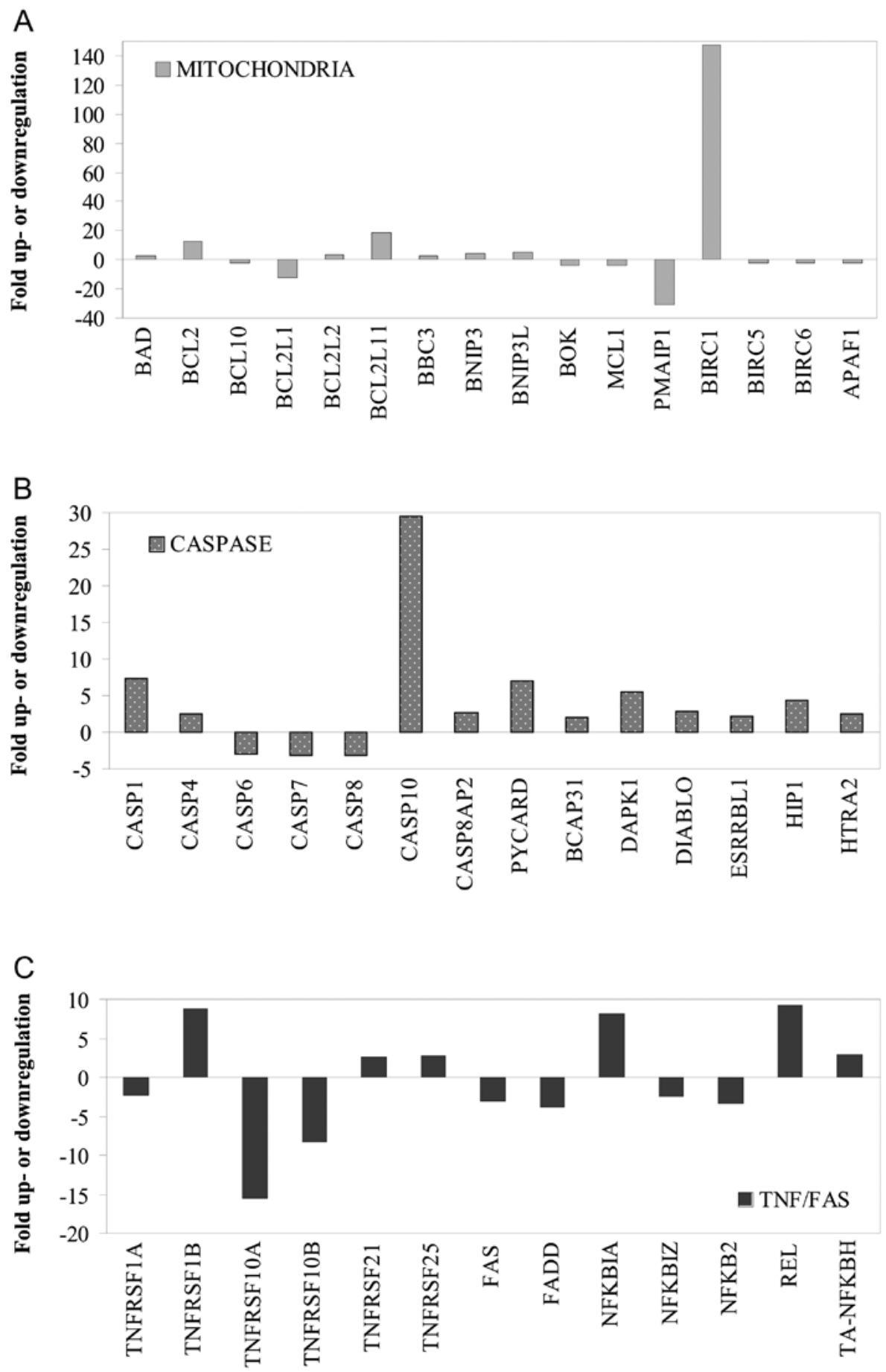

Figure 1. Gene expression changes in human glioblastoma tissue biopsy samples. Differentially expressed genes in tissue biopsy samples from patients with glioblastoma multiforme (GBM) as compared to the human astrocyte cell line (used as a reference), are divided into 3 indicated general subgroups according to coded proteins: (A) mitochondrial membrane-associated proteins, (B) caspases and their associated proteins and (C) tumor necrosis factor (TNF)/FAS receptor pathway.

$D A P K 1, H I P 1, D I A B L O$ and $B C A P 31$. Less substantial changes in expression were observed for the ESRRBLI and HTRA2 genes; these changes were not statistically significant (Table II).

\section{Discussion}

Glioblastomas are the most common and the most malignant brain tumors in adults and are often resistant to radiotherapy and chemotherapy (53). According to WHO, glioblastomas are clas- sified as malignant at grade IV (3). Searching for new markers and treatment targets is the purpose of many studies. However, the aim of the present study was to analyze pro-apoptotic and anti-apoptotic gene expression using a commercially available set of genes included in the microarray cards of the TaqMan ${ }^{\circledR}$ Human Apoptosis Array (Applied Biosystems). The results of our study demonstrated the anti-apoptotic properties of the tissue biopsy samples from patients diagnosed with GBM, and it was clear that the expression patterns of the apoptotic genes 
Table II. Microarray-based gene expression changes in tissue biopsy samples from patients with GBM.

\begin{tabular}{|c|c|c|c|}
\hline Gene name & Fold change & p-value & Gene description \\
\hline \multicolumn{4}{|c|}{ BCL-2 family-regulated pathway } \\
\hline BAD & 2.33 & 0.1395 & Bcl-2 associated agonist of cell death \\
\hline BCL2 & 12.45 & 0.0012 & B-cell CLL/lymphoma 2 \\
\hline BCL10 & -2.54 & 0.1654 & B-cell CLL/lymphoma 10 \\
\hline BCL2L1 & -12.03 & 0.0023 & BCL2-like 1 \\
\hline BCL2L2 & 3.23 & 0.0222 & BCL2-like 2 \\
\hline BCL2L11 & 18.32 & 0.0001 & BCL2-like 11 (apoptosis facilitator) \\
\hline BBC3 & 2.51 & 0.0177 & BCL2 binding component 3 \\
\hline BNIP3 & 4.45 & 0.0027 & BCL2/adenovirus E1B $19 \mathrm{kDa}$ interacting protein 3 \\
\hline BNIP3L & 5.09 & 0.0026 & BCL2/adenovirus E1B $19 \mathrm{kDa}$ interacting protein 3-like \\
\hline BOK & -3.94 & 0.0137 & BCL2-related ovarian killer \\
\hline MCL1 & -3.64 & 0.0171 & Myeloid cell leukemia sequence 1 (BCL2-related) \\
\hline PMAIP1 & -30.78 & 0.0015 & Phorbol-12-myristate-13-acetate-induced protein 1 \\
\hline \multicolumn{4}{|c|}{ TNF receptor pathway } \\
\hline TNFRSF1A & -2.34 & 0.0628 & Tumor necrosis factor receptor superfamily, member $1 \mathrm{~A}$ \\
\hline TNFRSF1B & 8.82 & 0.0173 & Tumor necrosis factor receptor superfamily, member 1B \\
\hline TNFRSF10A & -15.58 & 0.0045 & Tumor necrosis factor receptor superfamily, member $10 \mathrm{~A}$ \\
\hline TNFRSF10B & -8.30 & 0.0003 & Tumor necrosis factor receptor superfamily, member $10 \mathrm{~B}$ \\
\hline TNFRSF21 & 2.60 & 0.0741 & Tumor necrosis factor receptor superfamily, member 21 \\
\hline TNFRSF25 & 2.80 & 0.1072 & Tumor necrosis factor receptor superfamily, member 25 \\
\hline FAS & -3.00 & 0.0222 & Fas (TNF receptor superfamily, member 6) \\
\hline FADD & -3.87 & 0.0261 & Fas (TNFRSF6)-associated via death domain \\
\hline \multicolumn{4}{|l|}{ Caspases } \\
\hline CASP1 & 7.41 & 0.0161 & Caspase-1, apoptosis-related cysteine peptidase \\
\hline CASP4 & 2.47 & 0.0889 & Caspase-4, apoptosis-related cysteine peptidase \\
\hline CASP6 & -3.08 & 0.0034 & Caspase-6, apoptosis-related cysteine peptidase \\
\hline CASP7 & -3.17 & 0.0114 & Caspase-7, apoptosis-related cysteine peptidase \\
\hline CASP8 & -3.17 & 0.0594 & Caspase-8, apoptosis-related cysteine peptidase \\
\hline CASP10 & 29.46 & 0.0006 & Caspase-10, apoptosis-related cysteine peptidase \\
\hline CASP8AP2 & 2.74 & 0.0116 & CASP8 associated protein 2 \\
\hline \multicolumn{4}{|c|}{$\mathrm{NF}-\kappa \mathrm{B}$ signaling pathway } \\
\hline NFKBIA & 8.15 & 0.0042 & Nuclear factor of kappa light polypeptide gene enhancer in B-cells inhibitor alpha \\
\hline NFKBIZ & -2.40 & 0.1366 & Nuclear factor of kappa light polypeptide gene enhancer in B-cells inhibitor zeta \\
\hline NFKB2 & -3.31 & 0.0252 & Nuclear factor of kappa light polypeptide gene enhancer in B-cells 2 (p49/p100) \\
\hline REL & 9.22 & 0.0007 & v-rel reticuloendotheliosis viral oncogene homolog (avian) \\
\hline TA-NFKBH & 2.90 & 0.0037 & T-cell activation NFKB-like protein \\
\hline \multicolumn{4}{|l|}{ IAP family } \\
\hline BIRC1 & 147.09 & 0.0001 & Baculoviral IAP repeat-containing 1 \\
\hline BIRC5 & -2.02 & 0.0959 & Baculoviral IAP repeat-containing 5 (survivin) \\
\hline BIRC6 & -2.18 & 0.0031 & Baculoviral IAP repeat-containing 6 (apollon) \\
\hline \multicolumn{4}{|l|}{ CARD family } \\
\hline APAF1 & -2.35 & 0.0307 & Apoptotic peptidase activating factor \\
\hline PYCARD & 6.96 & 0.0442 & PYD and CARD domain containing \\
\hline \multicolumn{4}{|l|}{ Others } \\
\hline BCAP31 & 2.04 & 0.0454 & B-cell receptor-associated protein 31 \\
\hline DAPK1 & 5.44 & 0.0313 & Death-associated protein kinase 1 \\
\hline DIABLO & 2.76 & 0.0014 & Diablo homolog (Drosophila) \\
\hline ESRRBL1 & 2.19 & 0.1333 & Estrogen-related receptor $\beta$ like 1 \\
\hline HIP1 & 4.31 & 0.0215 & Huntingtin interacting protein 1 \\
\hline HTRA2 & 2.46 & 0.0633 & HtrA serine peptidase 2 \\
\hline
\end{tabular}

List of genes whose expression in tissue biopsy samples from patients with glioblastoma multiforme (GBM) differed from that in the human astrocyte cell line (used as a reference). The genes are divided into 7 subgroups: BCL-2 family-regulated pathway, TNF receptor pathway, caspases, $\mathrm{NF}-\mathrm{\kappa B}$ signaling pathway, IAP family, CARD family and others. Genes with a significant difference in expression were considered those with an average fold change of $\leq-2.0$ or $\geq 2.0$ and statistically significant differences were those with a corresponding $\mathrm{p}$-value $<0.05$. TNF, tumor necrosis factor; NF- $\mathrm{KB}$, nuclear factor- $\mathrm{\kappa B}$; IAP, inhibitor of apoptosis. 
differed significantly between the GBM tissue samples and the HA cell line (used as a reference; Table II). Our knowledge of the biological attributes and molecular phenotypes of GBM cells is still limited, and developing our understanding of these factors remains a major challenge worldwide. The gene expression signatures described in the present study may help broaden our understanding of the mechanisms responsible for malignant transformation and may increase our knowledge of GBM physiology.

Previous studies on human tumors have analyzed and confirmed the changes in $p 53$ gene expression, which are associated with programmed apoptotic cell death (54-57). Therefore, it can be said that alterations in apoptotic pathways play a key role in tumor formation and progression. Tumorigenesis can be driven by the deregulation and perturbation of apoptotic cell death and is one of the major reasons for the failure of conventional anticancer treatment $(32,58,59)$.

Human malignant gliomas express high levels of BCL-2 protein, which may thus provide glioblastoma cells with the ability to resist apoptosis $(11,60)$. The overexpression of BCL-2 provides cancer cells with a survival advantage in response to a wide range of apoptotic stimuli by inhibiting the release of mitochondrial cytochrome $c(30)$. A potential function of the BCL-2 protein in neuronal cells was first described by Reed et al (61). Consistent with these previous studies, we noted high levels of $B C L 2$ expression and the upregulation of $B C L 2 L 2(B C L-w)$ in human malignant GBM tissue biopsy samples, which may serve as essential protective factors against apoptosis. On the other hand, a statistically significant decrease in PMAIPI (NOXA) and BOK gene expression is indicative of the increased anti-apoptotic properties of GBM tumor tissue.

In the present study, our results demonstrated that the gene coding NAIP (BIRC1) exhibited the most pronounced statistically significant increase in expression $(\mathrm{FC}=147.09)$. Protein BIRC1, which is coded by this gene, prevents neuronal apoptosis and plays a role in neuronal survival under pathological conditions (62). NAIP is likely an essential protective factor that helps GBM cells avoid apoptotic cell death through the inhibition of caspase-7 (44).

The slight downregulation of $A P A F 1$ can negatively affect apoptosome formation and thus inhibit apoptotic cell death (49-52). The apoptosome stimulates caspases that initiate cell death and plays a critical role in human cell apoptosis $(30,63)$. Our results demonstrated that there was an increase in the expression of initiator caspase-10, and a less marked upregulation of associated caspases, caspase- 1 and caspase- 4 was also noted. However, caspase- 8 and the effector caspases, caspase- 6 and caspase- 7 do not seem to play an important role in apoptosis in GBM, as their expression was only slightly downregulated. Caspase-10 may not be capable of functionally replacing caspase- 8 unless it is present at very high levels. Although it seems likely that GBM tissues that express high levels of caspase-10 would have been sensitive to apoptosis, it does not necessarily follow that GBM tissue would also express higher levels of the effector caspases, caspases-8, -6 and -7 and would thus be resistant to apoptotic signals. It has previously been suggested that low endogenous levels of caspase- 8 are responsible for the resistance of GBM cells to death ligands (64). The upregulation of caspase-10 would not necessarily functionally substitute caspase- 8 or increase the expression levels of its gene in the apoptotic signaling pathway in GBM tissue. The frequent occurrence of low levels of caspase- 8 in gliomas may complicate the future development of therapies for patients with this malignancy.

The extrinsic apoptotic pathway is triggered by the TNF family, which is responsible for the transmission of signals from extracellular death ligands through appropriate death receptors to the cells apoptotic machinery (29). The significance of the $\mathrm{NF}-\kappa \mathrm{B}$ signaling pathway in GBM cells has been reported in several studies. Active NF- $\kappa \mathrm{B}$ stimulates the expression of genes that maintain cellular proliferation and protects cells from the conditions leading to apoptosis. The involvement of the NF- $\mathrm{B}$ signaling pathway in responses to DNA damage mediates chemoresistance in GBM cells $(28,65,66)$. Our data revealed chanes in the expression of various members of the TNF and $\mathrm{NF}-\kappa \mathrm{B}$ signaling pathway. Pro-caspase- 8 associates with FADD to form the death-inducing signaling complex (DISC), whereby pro-caspase- 8 converts itself into an active cleaved form and activates effector caspase-3 (67). It has previously been shown that GBM cells are resistant to Fas-related apoptosis, exhibiting absent or low levels of caspase- 8 or caspase-3 $(11,64)$. We observed similar results, as caspase- 8 was downregulated in the GBM samples we examined. The role of the extrinsic apoptotic pathway in human GBM has not yet been systematically investigated; however, previous studies have demonstrated the inhibition of this pathway in high-grade gliomas $(21,64,68)$. Our results revealed a statistically significant downregulation in the expression of TNFRSF10A, TNFRSF10B, FADD and FAS, and this can affect DISC formation or caspase- 8 activation and may provide GBM cells with the ability to avoid apoptotic cell death.

In the present study, we demonstrate that tissue biopsy samples obtained from patients diagnosed with GBM are more resistant to apoptosis than human astrocytes. We assume that apoptosis resistance of glioblastoma cells can be partially based on the upregulation of anti-apoptotic genes (BCL2, $B C L 2 L 2, B I R C 1)$ and the downregulation of pro-apoptotic genes (PMAIP1, BOK, CASP6, CASP7, CASP8, APAF1). The improved characterization of the differences in apoptotic gene expression between astrocytes and GBM cells may lead to improvements in the diagnosis, prognosis and treatment of this disease. Glioblastoma cells have totally defective apoptotic signaling pathways compared to astrocytes, and this results in a rise in cell proliferation and uncontrolled tumor growth. Monitoring differentially expressed apoptosis-associated genes in tissue biopsy samples from patients with GBM may broaden our understanding of the metabolism of brain tumor cells, and may aid in the identification of differentially expressed apoptosis-associated genes in human cell lines which may in turn provide a useful research tool for investigating the experimental model of CNS cells. Further studies are warranted in order to evaluate the therapeutic potential of apoptotic gene expression in relation to the treatment of GBM.

\section{Acknowledgements}

This work was supported by grant APVV-0224-12 and by project 'Increasing Opportunities for Career Growth in Research and Development in the Field of Medical Sciences', ITMS: 26110230067, co-funded from EU sources and European Social Fund. 


\section{References}

1. Richterová R, Jurečeková J, Evinová A, Kolarovszki B, Benčo M, De Riggo J, Sutovský J, Mahmood S, Račay P, Dobrota D: Most frequent molecular and immunohistochemical markers present in selected types of brain tumors. Gen Physiol Biophys 33: 259-279, 2014

2. Ricard D, Idbaih A, Ducray F, Lahutte M, Hoang-Xuan K and Delattre JY: Primary brain tumours in adults. Lancet 379 1984-1996, 2012.

3. Louis DN, Ohgaki H, Wiestler OD, Cavenee WK, Burger PC, Jouvet A, Scheithauer BW and Kleihues P: The 2007 WHO classification of tumours of the central nervous system. Acta Neuropathol 114: 97-109, 2007.

4. Persano L, Rampazzo E, Basso G and Viola G: Glioblastoma cancer stem cells: role of the microenvironment and therapeutic targeting. Biochem Pharmacol 85: 612-622, 2013.

5. Persson AI, Petritsch C, Swartling FJ, Itsara M, Sim FJ, Auvergne R, Goldenberg DD, Vandenberg SR, Nguyen KN Yakovenko S, et al: Non-stem cell origin for oligodendroglioma. Cancer Cell 18: 669-682, 2010.

6. Kreso A and Dick JE: Evolution of the cancer stem cell model. Cell Stem Cell 14: 275-291, 2014.

7. Pointer KB, Clark PA, Zorniak M and Arlfaei BM: Glioblastoma cancer stem cells: Biomarker and therapeutic advances. Neurochem Int 71: 1-7, 2014.

8. Schonberg DL, Lubelski D, Miller TE and Rich JN: Brain tumor stem cells: Molecular characteristics and their impact on therapy. Mol Aspects Med 39: 82-101, 2014.

9. Jovčevska I, Kočevar N and Komel R: Glioma and glioblastoma how much do we (not) know? Mol Clin Oncol 1: 935-941, 2013.

10. Ohgaki $\mathrm{H}$ and Kleihues P: Genetic pathways to primary and secondary glioblastoma. Am J Pathol 170: 1445-1453, 2007.

11. Tirapelli LF, Bolini PH, Tirapelli DP, Peria FM, Becker AN, Saggioro FP and Carlotti CG Jr: Caspase-3 and Bcl-2 expression in glioblastoma: an immunohistochemical study. Arq Neuropsiquiatr 68: 603-607, 2010.

12. Ohgaki $\mathrm{H}$ and Kleihues $\mathrm{P}$ : Genetic alterations and signaling pathways in the evolution of gliomas. Cancer Sci 100: 2235-2241, 2009.

13. Iacob G and Dinca EB: Current data and strategy in glioblastoma multiforme. J Med Life 2: 386-393, 2009.

14. Ahmed R, Oborski MJ, Hwang M, Lieberman FS and Mountz JM: Malignant gliomas: current perspectives in diagnosis, treatment, and early response assessment using advanced quantitative imaging methods. Cancer Manag Res 6: 149-170, 2014.

15. Bralten LBC and French PJ: Genetic alterations in glioma. Cancers 3: 1129-1140, 2011

16. Kleihues P,Louis DN, Scheithauer BW, Rorke LB, Reifenberger G Burger PC and Cavenee WK: The WHO classification of tumors of the nervous system. J Neuropathol Exp Neurol 61: 215-225, 2002.

17. Barazzuol L, Jena R, Burnet NG, Jeynes JC, Merchant MJ, Kirkby KJ and Kirkby NF: In vitro evaluation of combined temozolomide and radiotherapy using $\mathrm{X}$ rays and high-linear energy transfer radiation for glioblastoma. Radiat Res 177: 651-662, 2012

18. Fruehauf JP, Brem H, Brem S, Sloan A, Barger G, Huang W and Parker R: In vitro drug response and molecular markers associated with drug resistance in malignant gliomas. Clin Cancer Res 12: 4523-4532, 2006.

19. Westhoff MA, Brühl O, Nonnenmacher L, Karpel-Massler G and Debatin KM: Killing me softly - future challenges in apoptosis research. Int J Mol Sci 15: 3746-3767, 2014.

20. Redmond KM, Wilson TR, Johnston PG and Longley DB: Resistance mechanisms to cancer chemotherapy. Front Biosci 13: 5138-5154, 2008.

21. Riffkin CD, Gray AZ, Hawkins CJ, Chow CW and Ashley DM: Ex vivo pediatric brain tumors express Fas (CD95) and FasL (CD95L) and are resistant to apoptosis induction. Neuro Oncol 3 229-240, 2001

22. Krajewski S, Krajewska M, Ehrmann J, Sikorska M, Lach B Chatten J and Reed JC: Immunohistochemical analysis of bcl-2, $\mathrm{Bcl}-\mathrm{X}, \mathrm{Mcl}-1$, and Bax in tmors of central and peripheral nervous system origin. Am J Pathol 150: 805-814, 1997.

23. Kogel D, Fulda S and Mittelbronn M: Therapeutic exploitation of apoptosis and autophagy for glioblastoma. Anticancer Agents Med Chem 10: 438-449, 2010.

24. Portt L, Norman G, Clapp C, Greenwood M and Greenwood MT: Anti-apoptosis and cell survival: a review. Biochim Biophys Acta 1813: 238-259, 2011
25. Fulda S and Debatin KM: Extrinsic versus intrinsic apoptosis pathways in anticancer chemotherapy. Oncogene 25: 4798-4811, 2006.

26. Putcha GV, Harris CA, Moulder KL, Easton RM, Thompson CB and Johnson EM Jr: Intrinsic and extrinsic pathway signaling during neuronal apoptosis: lessons from the analysis of mutant mice. J Cell Biol 157: 441-453, 2002.

27. Thomas S, Quinn BA, Das SK, Dash R, Emdad L, Dasgupta S, Wang XY, Dent P, Reed JC, Pellecchia M, Sarkar D and Fisher PB: Targeting the Bcl-2 family for cancer therapy. Expert Opin Ther Targets 17: 61-75, 2013.

28. Tchoghadjian A, Jennewein C, Eckhardt I, Momma S, Branger DF and Fulda S: Smac mimetic promotes glioblastoma cancer stem-like cell differntiation by activating NF- $\kappa \mathrm{B}$. Cell Death Differ 21: 735-747, 2014

29. Sayers TJ: Targeting the extrinsic apoptosis signaling pathway for cancer therapy. Cancer Immunol Immunother 60: 1173-1180, 2011.

30. Wong RS: Apoptosis in cancer: from pathogenesis to treatment. J Exp Clin Cancer Res 30: 87, 2011.

31. Hervouet E, Cheray M, Vallette FM and Cartron PF: DNA methylation and apoptosis resistance in cancer cells. Cells 2: 545-573, 2013.

32. Kelly G and Strasser A: The role of Bcl-2 and its pro-survival relatives in tumourigenesis and cancer therapy. Cell Death Differ 18: 1414-1424, 2011.

33. Llambi F and Green DR: Apoptosis and oncogenesis: give and take in the BCL-2 family. Curr Opin Genet Dev 21: 12-20, 2011.

34. Kim H, Tu HC, Ren D, Takeuchi O, Jeffers JR, Zambetti GP, Hsieh JJ and Cheng EH: Stepwise activation of Bax and Bak by tBid, Bim, and Puma initiates mitochondrial apoptosis. Mol Cell 36: 487-499, 2009.

35. Bender A, Opel D, Naumann I, Kappeler R, Friedman L, von Schweinitz D, Debatin KM and Fulda S: PI3K inhibitors prime neuroblastoma cells for chemotherapy by shifting the balance towards pro-apoptotic $\mathrm{Bcl}-2$ proteins and enhanced mitochondrial apoptosis. Oncogene 30: 494-503, 2011.

36. Ghobrial IM, Witzig TE and Adjei AA: Targeting apoptosis pathways in cancer therapy. Cancer J Clin 55: 178-194, 2005.

37. Zubor P, Hatok J, Moricova P, Kapustova I, Kajo K, Mendelova A, Sivonova MK and Danko J: Gene expression profiling of histologically normal breast tissue in females with human epidermal growth factor receptor 2-positive breast cancer. Mol Med Rep 11: 1421-1427, 2015

38. Zubor P, Hatok J, Galo S, Dokus K, Klobusiakova D, Danko J and Racay P: Anti-apoptotic and pro-apoptotic gene expression evaluated from eutopic endometrium in the proliferative phase of the menstrual cycle among women with endometriosis and healthy controls. Eur J Obstet Gynecol Reprod Biol 145: 172-176, 2009.

39. Vitucci M, Hayes DN and Miller CR: Gene expression profiling of gliomas: merging genomic and histopathological classification for personalised therapy. Br J Cancer 104: 545-553, 2011.

40. Cancer Genome Atlas Research Network: Comprehensive genomic characterization defines human glioblastoma genes and core pathways. Nature 455: 1061-1068, 2008.

41. Shiozaki EN and Shi Y: Caspases, IAPs and Smac/DIABLO: mechanisms from structural biology. Trends Biochem Sci 29: 486-494, 2004.

42. Shi Y: Mechanisms of caspase activation and inhibition during apoptosis. Mol Cell 9: 459-470, 2002.

43. Verhagen AM, Coulson EJ and Vaux DL: Inhibitor of apoptosis proteins and their relatives: IAPs and other BIRPs. Genome Biol 2: REVIEWS3009, 2001.

44. Maier JK, Lahoua Z, Gendron NH, Fetni R, Johnston A, Davoodi J, Rasper D, Roy S, Slack RS, Nicholson DW and MacKenzie AE: The neuronal apoptosis inhibitory protein is a direct inhibitor of caspases 3 and 7. J Neurosci 22: 2035-2043, 2002.

45. Holcik M, Thompson CS, Yaraghi Z,Lefebvre CA, MacKenzie AE and Korneluk RG: The hippocampal neurons of neuronal apoptosis inhibitory protein 1 (NAIP1)-deleted mice display increased vulnerability to kainic acid-induced injury. Proc Natl Acad Sci USA 97: 2286-2290, 2000.

46. Ouyang L, Shi Z, Zhao S, Wang FT, Zhou TT, Liu B and Bao JK: Programmed cell death pathways in cancer: a review of apoptosis, autophagy and programmed necrosis. Cell Prolif 45: 487-498, 2012.

47. Ghavami S, Hashemi M, Ande SR, Yeganeh B, Xiao W Eshraghi M, Bus CJ, Kadkhoda K, Wiechec E, Halayko AJ and Los M: Apoptosis and cancer: mutations within caspase genes. J Med Genet 46: 497-510, 2009.

48. Kurokawa M and Kornbluth S: Caspases and kinases in a death grip. Cell 138: 838-854, 2009. 
49. Tanase C, Albulescu R, Codrici E, Calenic B, Popescu ID, Mihai S, Necula L, Cruceru ML and Hinescu ME: Decreased expression of APAF-1 and increased expression of cathepsin B in invasive pituitary adenoma. Onco Targets Ther 8: 81-90, 2014.

50. Yuan S and Akey CW: Apoptosome structure, assembly and procaspase activation. Structure 21: 501-515, 2013.

51. Mouhamad S, Galluzzi L, Zermati Y, Castedo M and Kroemer G: Apaf-1 deficiency causes chromosomal instability. Cell Cycle 24: 3103-3107, 2007.

52. Li P, Nijhawan D, Budihardjo I, Srinivasula SM, Ahmad M, Alnemri ES and Wang X: Cytochrome $c$ and dATP-dependent formation of Apaf-1/caspase-9 complex initiates an apoptotic protease cascade. Cell 91: 479-489, 1997.

53. Karsy M, Neil JA, Guan J, Mark MA, Colman H and Jensen RL: A practical review of prognostic correlations of molecular biomarkers in glioblastoma. Neurosurg Focus 38: E4, 2015.

54. Wei B, Wang I, Du Ch, Hu G, Wang L, Jin Y and Kong D Identification of differentially expressed genes regulated by transcription factors in glioblastomas by bioinformatics analysis. Mol Med Rep 11: 2548-2554, 2015.

55. Stancheva G, Goranova T, Laleva M, Kamenova M, Mitkova A, Velinov N, Poptodorov G, Mitev V, Kaneva R and Gabrovsky N: IDH1/IDH2 but not TP53 mutations predict prognosis in Bulgarian glioblastoma patients. Biomed Res Int 2014: 654727, 2014.

56. England B, Huang T and Karsy M: Current understanding of the role and targeting of tumor suppressor p53 in glioblastoma multiforme. Tumor Biol 34: 2063-2074, 2013.

57. Li J, Di Ch, Mattox AK, Wu L and Adamson DC: The future role of personalized medicine in the treatment of glioblastoma multiforme. Pharmacogen Personal Med 3: 111-127, 2010.

58. Vogler M: Targeting BCL2 proteins for the treatment of solid tumours. Advances in Medicine 2014: ID 943648, 2014.

59. Elmore S: Apoptosis: a review of programmed cell death. Toxicol Pathol 35: 495-516, 2007.

60. Tagscherer KE, Fassl A, Campos B, Farhadi M, Kraemer A, Böck BC, Macher-Goeppinger S, Radlwimmer B, Wiestler OD, Herold-Mende C and Roth W: Apoptosis-based treatment of glioblastomas with ABT-737, a novel small molecule inhibitor of Bcl-2 family proteins. Oncogene 27: 6646-6656, 2008.
61. Reed JC, Meister L, Tanaka S, Cuddy M, Yum S, Geyer C and Pleasure D: Differential expression of bcl2 protooncogene in neuroblastoma and others human tumor cell lines of neural origin. Cancer Res 51: 6529-6538, 1991.

62. Mercer EA, Korhonen L, Skoglösa Y, Olsson PA, Kukkonen JP and Lindholm D: NAIP interacts with hippocalcin and protects neurons against calcium-induced cell death through caspase-3-dependent and -independent pathways. EMBO J 19: 3597-3607, 2000.

63. Wen X, Lin ZQ, Liu B and Wei YQ: Caspase-mediated programmed cell death pathways as potential therapeutic targets in cancer. Cell Prolif 45: 217-224, 2012.

64. Ashley DM, Riffkin CD, Muscat AM, Knight MJ, Kaye AH, Novak $U$ and Hawkins CJ: Caspase 8 is absent or low in many ex vivo gliomas. Cancer 104: 1487-1496, 2005.

65. Yoshino A, Ogino A, Yachi K, Ohta T, Fukushima T, Watanabe T, Katayama Y, Okamoto Y, Naruse N, Sano E and Tsumoto K: Gene expression profiling predicts response to temozolomide in malignant gliomas. Int J Oncol 36: 1367-1377, 2010.

66. Bredel M, Bredel C, Juric D, Duran GE, Yu RX, Harsh GR, Vogel H, Recht LD, Scheck AC and Sikic BI: Tumor necrosis factor-alpha-induced protein 3 as a putative regulator of nuclear factor-kappaB-mediated resistance to O6-alkylating agents in human glioblastomas. J Clin Oncol 24: 274-287, 2006.

67. Saggioro FP, Neder L, Stávale JN, Paixao-Becker AN, Malheiros SM, Soares FA, Pittella JE, Matias CC, Colli BO, Carlotti CG Jr, et al: Fas, FasL, and cleaved caspases 8 and 3 in glioblastomas: a tissue microarray-based study. Pathol Res Pract 210: 267-273, 2014.

68. Siegelin MD, Gaiser T and Siegelin Y: The XIAP inhibitor Embelin enhances TRAIL-mediated apoptosis in malignant glioma cells by down-regulation of the short isoform of FLIP. Neurochem Int 55: 423-30, 2009. 